\title{
Pelatihan Penggunaan Schoology Pada Guru SMA Negeri 9 Samarinda
}

\author{
Nurdin Arifin, Natalia Gita Intan Trinova, Dina Riani Tiku Belo \\ Program Studi PGSD, Universitas Widya Gama Mahakam Samarinda, Indonesia \\ nurdin.arifin91@gmail.com
}

\begin{abstract}
ABSTRAK
Kegiatan ini berupaya untuk memberikan pembelajaran yang inovatif dan efisien ditengah pembelajaran secara daring yang terjadi saat ini dikarenakan pandemi COVID-2019. Schoology merupakan salah satu Learning Management System (LMS) yang membantu peserta didik dan pendidik dalam kegiatan belajar mengajar secara daring. Schoology adalah layanan jejaring sosial dan lingkungan pembelajaran virtual untuk institusi sekolah dan pendidikan tinggi yang memungkinkan pengguna untuk membuat, mengelola, dan berbagi konten akademik. Kegiatan ini dilaksanakan di SMA Negeri 9 Samarinda yang dihadiri sebanyak 10 orang guru. Dipilihnya SMA Negeri 9 Samarinda merupakan sekolah Adiwiyata Nasional tahun 2019 serta sekolah sudah dilengkapi fasilitas penunjang kegiatan belajar mengajar yang dapat memanfaatkan teknologi informasi. Metode dalam kegiatan pengabdian ini dilaksanakan dalam empat tahap yakni metde ceramah, diskusi dan tanya jawab, simulasi/praktik, dan evaluasi. Hasil kegiatan pendampingan ini yakni bahwa para peserta pelatihan telah mempunyai kemmpuan dan pengetahuan untuk menggunakan dan mengelola kegiatan pembelajaran dengan menggunakan LMS schoology, para peserta (guru) telah memiliki kelas pembelajaran dengan menggunakan LMS schoology, serta para peserta pelatihan yang merupakan guru telah membuat dan mampu mengembangan konten pembelajaran dengan menggunakan LMS schoology.
\end{abstract}

Kata Kunci: Learning Management System, LMS, Schoology, Sekolah

\section{PENDAHULUAN}

Beberapa tahun terakhir ini, teknologi canggih telah memfasilitasi pembelajaran daring sebagai mode pembelajaran yang baru muncul. Pelajar dapat mengakses lingkungan belajar daring untuk belajar di mana saja melalui menggunakan Internet dan berbagai platform pembelajaran daring tanpa kendala waktu. Mode pembelajaran ini memungkinkan fleksibilitas yang lebih besar dalam lingkungan belajar. Menyediakan banyak bahan atau video pengajaran daring bagi peserta didik untuk menonton adalah karakteristik umum dari berbagai platform pembelajaran daring, yang juga menggabungkan manfaat belajar tanpa batasan waktu dan tempat. Dengan penggunaan komputer dan Internet, peserta didik mendapatkan pengalaman belajar. Selain itu pembelajaran daring memungkinkan peserta didik untuk memiliki lebih banyak waktu untuk memahami materi kelas dengan berulang kali menonton kursus (Hwang et al., 2020).

Mengenai lingkungan pembelajaran daring, sebagian besar dikategorikan ke dalam lingkungan pembelajaran yang dipersonalisasi, artinya, siswa mengamanisasi waktu mereka mengenai jalur pembelajaran yang diberikan oleh platform pembelajaran daring selama studi mereka (Hwang et al., 2020). Meskipun lingkungan belajar semacam ini menawarkan lingkungan belajar yang terbuka. Misalnya, mereka menyarankan agar pembelajaran daring memberikan peringatan pembelajaran kepada siswa dan membimbing mereka untuk pembelajaran mereka (Lu et al., 2018), dengan tujuan untuk mempertahankan motivasi belajar daring mereka, memberikan berbagi pengetahuan dengan rekan-rekan atau menetapkan mekanisme diagnosis otomatis serta memberikan umpan balik instan untuk menyelesaikan masalah pembelajaran (Hwang et al., 2020). 
Pembelajaran daring berarti bahwa pelajar menggunakan Internet untuk mempelajari dan mendapatkan pengalaman belajar dengan menggunakan komputer ataupun smartphone. Melalui penggunaan website untuk belajar, peserta didik dapat melakukan pembelajaran jarak jauh di mana saja, waktu dan lokasi tidak akan lagi menjadi hambatan antara guru dan peserta didik. Mode pembelajaran ini telah meningkat kesempatan belajar bagi peserta didik atau peningkatan keterhubungan, fleksibilitas, dan interaksi selama kegiatan pembelajaran (Hwang et al., 2020).

Beberapa tahun terakhir, orang-orang dengan latar belakang yang beragam telah berinvestasi dalam pembelajaran daring karena popularitasnya, dan mereka ingin membuktikan efek pembelajaran daring dengan menganalisis parameter yang berbeda. Wang (2010) mengembangkan pendekatan pembelajaran daring untuk meningkatkan efektivitas belajar siswa dengan penyediaan ilustrasi daring. Panduan yang benar disediakan untuk membantu siswa dalam masalah menggunakan pendekatan cepat lulus. Wang (2014) mengembangkan pendekatan pembelajaran daring berbasis penilaian untuk membantu siswa selama proses pembelajaran daring. Penilaian diagnostik dua tingkat ini membantu siswa dalam mengklarifikasi dan memahami pembelajaran konsep; semakin banyak, ini meningkatkan kinerja pembelajaran mereka.

Meskipun banyak keuntungan bagi pengguna untuk melakukan pembelajaran daring, para peneliti telah menunjukkan masalah dalam pembelajaran daring lingkungan hidup (Rowe et al, 2019). Misalnya, guru tidak dapat memahami proses belajar siswa karena kurangnya interaksi tatap muka (Chen, Hwang, \& Chang, 2019). Niat dan motivasi daring pembelajaran akan berkurang jika platform pembelajaran daring tidak dapat memberikan umpan balik dan bimbingan instan kepada siswa (Muuro, et al., 2014). Di sisi lain, disiplin diri adalah salah satu tantangan terbesar yang dihadapi siswa dalam pembelajaran daring lingkungan (Lung-Guang, 2019). Sulit bagi siswa yang memiliki rencana untuk proses pembelajaran daring yang diarahkan sendiri untuk belajar terus menerus di lingkungan belajar daring. Mereka mudah dipengaruhi oleh media non-studi lainnya, dan cenderung tidak mendapatkan pembelajaran pengalaman di lingkungan belajar daring (Henderikx et al, 2019). Semua masalah ini harus diselesaikan dengan strategi atau bimbingan pembelajaran yang efektif yang diberikan oleh pendidik dan peneliti, dengan tujuan untuk menjaga niat peserta didik pembelajaran daring.

Learning Management System (LMS), dapat melibatkan aplikasi perangkat lunak dan teknologi berbasis web yang digunakan oleh fakultas dan untuk mengakses, merencanakan, mengimplementasikan, melengkapi, memantau, dan menilai pembelajaran atau berkomunikasi tentang pembelajaran (Masadeh \& Elfeky, 2016). LMS memiliki banyak jenis seperti Moodle, Canvas, Blackboard, dan Desire2Learn yang semuanya telah menjadi kunci komponen dalam melaksanakan pengajaran (AlJarrah, Thomas, \& Shehab, 2018). Selanjutnya, LMS telah menjadi alat untuk membuat, mendistribusikan, melacak, dan mengelola berbagai jenis pelatihan dan materi pendidikan (Mershad \& Wakim, 2018), yang secara luas digunakan dalam pendidikan tinggi dan menawarkan gerbang pengajaran dan pembelajaran yang dipromosikan teknologi inovatif (Sinclair \& Aho, 2018).

Mendigitalkan dan mengotomatiskan banyak fungsi pengajaran dan kegiatan pedagogis sebenarnya adalah salah satu dari banyak manfaat LMS (Anderson \& Dron, 2018). Dengan demikian, siswa dapat menggunakan LMS untuk mencoba banyak sumber belajar yang ditawarkan oleh instruktur mereka dan sementara itu berinteraksi dengan rekan-rekan mereka (Homavazir \& Gopal, 2018).

Schoology merupakan salah satu Learning Management System (LMS) yang membantu peserta didik dan pendidik dalam kegiatan belajar mengajar secara daring. Schoology adalah layanan jejaring sosial dan lingkungan pembelajaran virtual untuk institusi sekolah dan pendidikan tinggi K-12 yang memungkinkan pengguna untuk membuat, mengelola, dan berbagi konten akademik. Schoology dapat membantu guru menghubungi siswa dengan 
pekerjaan rumah dan lainnya dengan memungkinkan guru memposting pengingat atau pembaruan harian, mengirim pesan kepada siswa, mengelola tugas di kalender, memasukkan tugas baru kapan saja, dan bahkan melakukan ujian secara daring. Sehingga dengan adanya kegiatan pengabdian masyarakat ini, diharapkan pendidik khususnya di SMA Negeri 9 Samarinda mendapatkan pengetahuan tentang penggunaan dan mengaplikasikan LMS schoology.

\section{METODE PELAKSANAAN}

Tahapan metode yang digunakan dalam kegiatan ini yakni 1) metode ceramah, dimana dipilih untk memberikan penjelasan mengenai schoology, cara mengelola, dan mengatur schoology; 2) Metode diskusi dan tanya jawab, sebagai upaya untuk transfer knowledge dan mengatasi permasalahan yang dialami oleh guru dalam kegiatan praktek; 3) Metode Simulasi, yakni dimana para peserta pelatihan untuk memberikan kesempatan untuk praktik. 4) Evaluasi, merupakan kegiatan akhir dimana untuk mengetahui bagaimana kegiatan ini berlangsung yang diperoleh dari respon dan antusias dari peserta pelatihan dengan penyelenggaraan kegiatan ini yang diukur melalui wawancara kepada peserta dan melalui lembar pengamatan selama kegiatan pelatihan berlangsung. Keberhasilan pelaksanaan kegiatan pengabdian kepada masyarakat dikatakan berhasil jika memiliki persentase minimal sebesar $75 \%$.

Adapun alur dari metode pelaksanaan kegiatan pengabdian masyarakat yang dilakukan sebagai berikut.

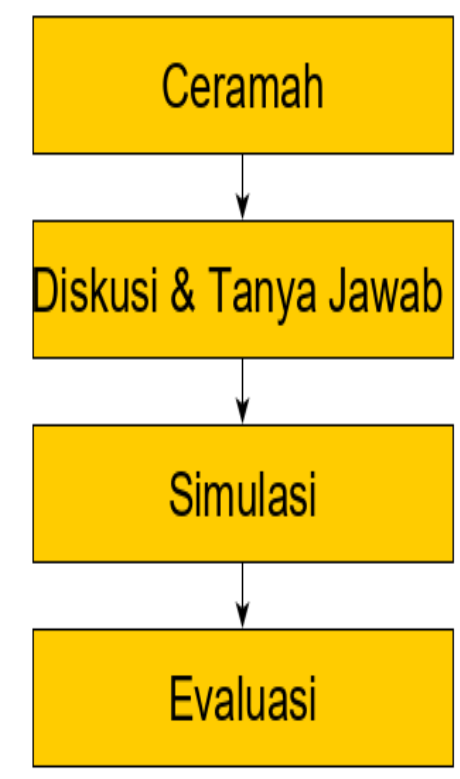

Gambar 1. Alur pelaksanaan Pengabdian

\section{HASIL DAN PEMBAHASAN}

Kegiatan pengabdian ini diikuti oleh 10 orang guru SMA Negeri 9 Samarinda yang merupakan perwakilan dari berbagai disiplin ilmu yang berbeda. Kegiatan ini hanya terbatas 10 orang guru dikarenakan dalam masa pandemi Covid-19 sehingga adanya pembatasan dan mematuhi protokol kesehatan pencegahan covid-19 dalam kegiatan pelatihan ini. Kegiatan dilaksanakan setiap hari sabtu selama bulan November yakni pada tanggal 7, 14, 21, dan 28.

Pada awal pelaksanaan, para guru diberikan penjelasan awal mengenai Learning Management System (LMS) khususnya schoology, kemudian kami memberikan modul yang 
telah dibuat ke seluruh peserta. Pada kegiatan awal ini dilakukan dengan ceramah yang dimana untuk menyamakan persepsi dan adanya timbal baik antara tim pengabdian kepada masyarakat dengan para peserta pelatihan terkait fitur-fitur pada schoology.

Pada proses mengakses schoology, guru dibimbing secara step by step dari tahap melakukan pendaftaran akun. Kemudian guru di perkenalkan dengan elemen-elemen atau fitur dari schoology serta bagaimana cara untuk mengisi/mengembangkan konten agar dapat menjadi media pembelajaran berbasis daring. Pada kegiatan ini juga adanya kegiatan diskusi dan tanya jawab yang dimana para peserta dapat bertanya mengenai kegunaan-kegunaan setiap fitur/elemen pada LMS schoology dan adanya sinkronisasi berupa sharing pengalaman belajar antara tim pengabdian kepada masyarakat dengan para guru SMA Negeri 9 Samarinda.

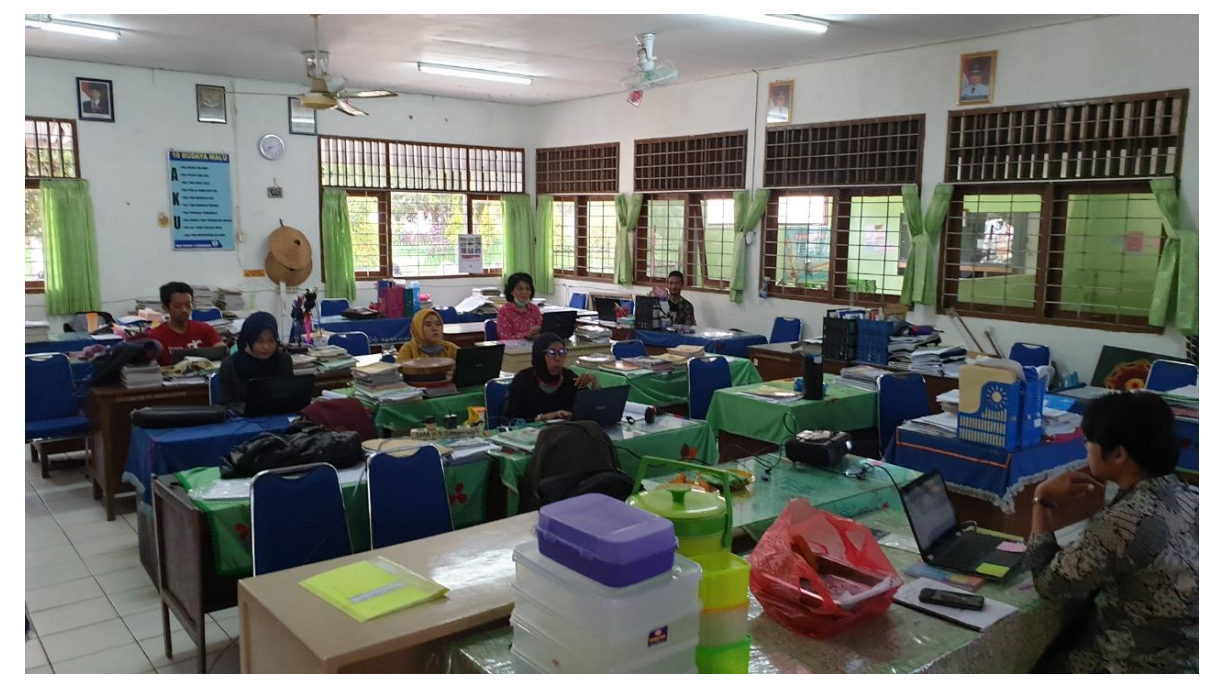

Gambar 2. Penyampaian materi oleh pemateri

Pada tahap simulasi, para peserta sudah memulai untuk mengorganisasikan konten pada schoology secara mandiri dan sesuai dengan mata pelajaran yang diampu. Para peserta mulai menggunkan fitur-fitur secara mandiri. Pada tahap ini ada peserta yang mengalami kesulitan maka para peserta mulai untuk mengajukan pertanyaan-pertanyaan mengenai bagaimana mengunggah materi yang kemudian tim pengabidan kepada masyarakat memfasilitasi untuk membantu memecahkan permasalahan yang dihadapi oleh peserta. Pendampingan yang dilakukan oleh tim berpusat pada kesulitan guru dalam melakukan pembuatan dan pengembangan media pembelajaran dengan menggunakan schoology. Baik dari cara membuat/menyusun tiap-tiap kelas, memasukkan materi pelajaran, hingga sampai pada tahap pembuatan soal untuk kuis ataupun ulangan harian yang nantinya akan dilaksanakan para peserta sebagai seorang guru pada saat pembelajaran. 


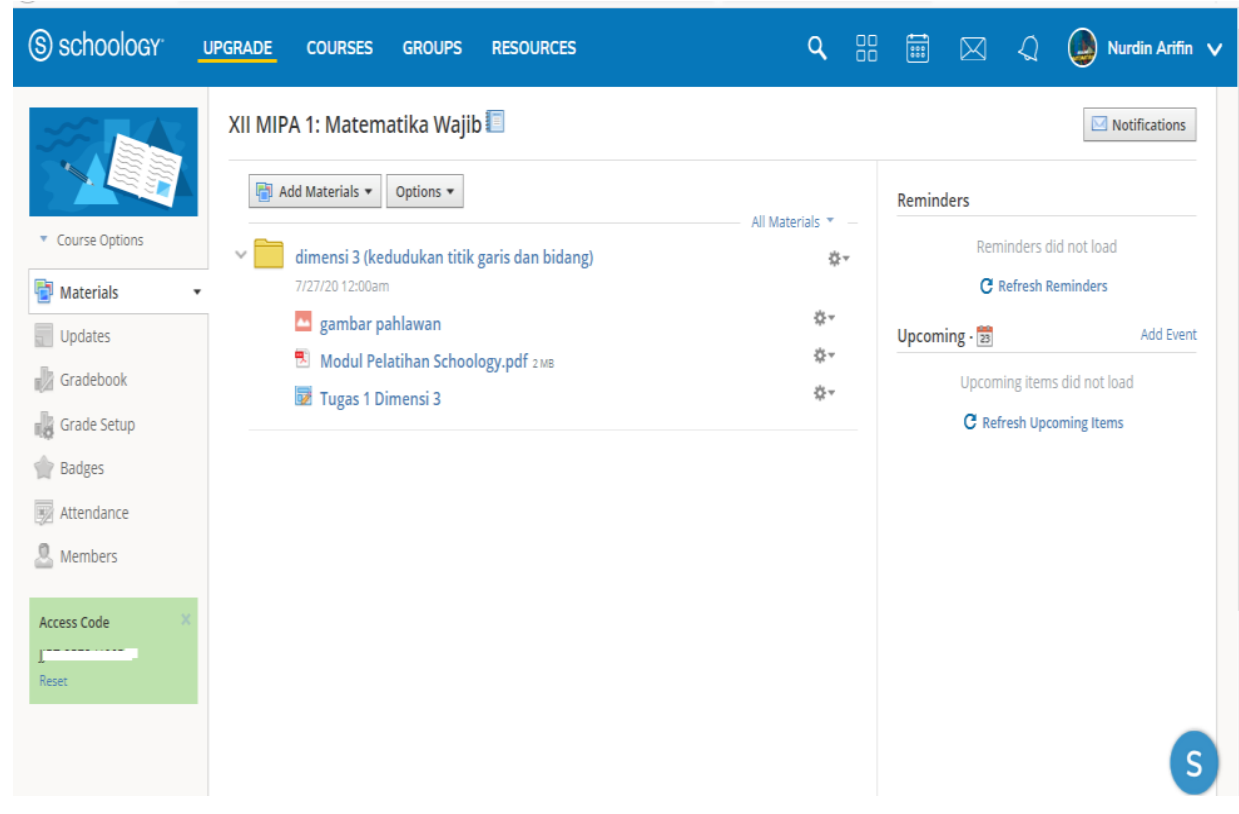

Gambar 3. Tampilan Schoology

Tahap evaluasi merupakan tahap terakhir dalam implementasi pengabdian masyarakat ini. Tahap ini dimulai dari tahap pendampingan sampai terbentuk media pembelajaran secara daring berbasis schoology yang dibuat oleh peserta dimana merupakan para guru. Pelaksanaan evaluasi dengan cara memberikan angket respon terkait proses kegiatan pelatihan penggunaan schoology dan berdasarkan penggunaan lembar observasi.

Tabel 1. Hasil Evaluasi Peserta Selama Kegiatan Pelatihan Menggunakan Schoology

\begin{tabular}{clcc}
\hline No & \multicolumn{1}{c}{ Aspek } & Persentase \\
\hline 1 & $\begin{array}{l}\text { Pemahaman terhadap konsep pembelajaran daring } \\
\text { menggunakan schoology }\end{array}$ & $90 \%$ \\
2 & $\begin{array}{l}\text { Penguasaan terhadap penggunaan LMS schoology } \\
3\end{array}$ & $82 \%$ \\
& $\begin{array}{l}\text { Pengelolaan konten yang tepat dalam menggunakan } \\
\text { schoology }\end{array}$ & $85 \%$ \\
4 & $\begin{array}{l}\text { Partisipasi peserta selama kegiatan } \\
5\end{array}$ & $\begin{array}{l}\text { Respon peserta terhadap pelaksanaan pelatihan } \\
\text { pembelajaran daring dengan schoology }\end{array}$ & $95 \%$ \\
\hline
\end{tabular}

Berdasarkan evluasi para peserta yakni guru-guru berdasarkan aspek pemahaman konsep pembelajaran daring, penguasaan penggunaan LMS schoology, pengelolaan konten yang tepat, dan partisipasi peserta menunjukan hasil yang baik dengan persentase keseluruhan lebih dari $80 \%$. Begitu pula dalam respon yang diberikan oleh peserta mengenai kegiatan ini yakni respon yang baik/positif, dikarenakan telah memberikan knowledge mengenai pembelajaran daring dengan menggunakan schoology, yang dimana peserta (guru) dalam masa pandemi Covid-19 hanya menggunakan aplikasi dari google yakni google classroom. Sehingga, harapannya kegiatan pengabdian seperti ini akan terus berlanjut dan dikembangkan terutama yang berkaitan dengan secara daring menggunakan learning management system. 


\section{KESIMPULAN DAN SARAN}

Berdasarkan kegiatan pengabdian kepada masyarakat ini dapat di simpulkan bahwa, para peserta pelatihan telah mempunyai kemampuan dan pengetahuan untuk menggunakan serta mengelola kegiatan pembelajaran dengan menggunakan LMS schoology, para peserta (guru) telah memiliki kelas pembelajaran dengan menggunakan LMS schoology, serta para peserta pelatihan yang merupakan guru telah membuat dan mampu mengembangan konten pembelajaran dengan menggunakan LMS schoology. Diharapkan nantinya dengan telah mengikuti kegiatan pelatihan dengan LMS schoology, akan membuat pembelajaran secara daring ataupun luring menjadi menarik, interaktif, dan inovatif serta menunjang kegiatan pada Sekolah Menengah Atas.

\section{DAFTAR PUSTAKA}

Anderson, T., \& Dron, J. (2018). Integrating learning management and social networking systems. Italian Journal of Educational Technology, 25(3), 5-19.

AlJarrah, A., Thomas, M. K., \& Shehab, M. (2018). Investigating temporal access in a flipped classroom: Procrastination persists. International Journal of Educational Technology in Higher Education, 15(1), 1.

Chen, M. R., A., Hwang, G., J., \& Chang, Y., Y. (2019). A reflective thinking-promoting approach to enhancing graduate students' flipped learning engagement, participation behaviors, reflective thinking and project learning outcomes. British Journal of Educational Technology, 50(5), 2288-2307.

Henderikx, M., et al. (2019). Factors influencing the pursuit of personal learning goals in MOOCs. Distance Education, 40(2), 187-204.

Homavazir, M. F., \& Gopal, R. (2018). A research study on the digitalisation of higher education and its impact on teaching and students assessment in commerce, management and science colleges in Mumbai. AADYA-Journal of Management and Technology (JMT), 8(1), 93-100

Hwang, G., Wang, S., \& Lai, C. (2020). Computers \& Education Effects of a social regulationbased daring learning framework on students ' learning achievements and behaviors in mathematics. Computers \& Education, 160 (August 2020), 104031. https://doi.org/10.1016/j.compedu.2020.104031

Lu, O. H. T., et al. (2018). Applying learning analytics for the early prediction of students' academic performance in blended learning. Educational Technology \& Society, 21(2), 220-232.

Lung-Guang, N. (2019). Decision-making determinants of students participating in MOOCs: Merging the theory of planned behavior and self-regulated learning model. Computers \& Education, 134, 50-62.

Masadeh, T. S. Y., \& Elfeky, A. I. M. (2016). Efficacy of open-source learning management systems in developing the teaching skills of english language student teachers. American Journal of Educational Research, 4(4), 329-337

Mershad, K., \& Wakim, P. (2018). A learning management system enhanced with internet of things applications. Journal of Education and Learning, 7(3), 23.

Muuro, M. E., Wagacha, W. P., Oboko, R., \& Kihoro, J. (2014). Students'Perceived challenges in an daring collaborative learning environment: A case of higher learning institutions in Nairobi, Kenya. International Review of Research in Open and Distance Learning, 15(6), $132-161$.

Rowe, M., et al. (2019). These may not be the courses you are seeking: A systematic review of open daring courses in health professions education. BMC Medical Education, 19(1). 
Sinclair, J., \& Aho, A.-M. (2018). Experts on super innovators: Understanding staff adoption of learning management systems. Higher Education Research \& Development, 37(1), $158-172$.

Wang, T. H. (2010). Web-based dynamic assessment: Taking assessment as teaching and learning strategy for improving students' e-learning effectiveness. Computers \& Education, 54(4), 1157-1166.

Wang, T. H. (2014). Developing an assessment-centered e-learning system for improving student learning effectiveness. Computers \& Education, 73, 189-203. 